\title{
PHOTOGRAMMETRY APPLIED TO PROBLEMATIC ARTEFACTS
}

\author{
C. Nicolae ${ }^{\text {a }}$, E. Nocerino ${ }^{\text {b }}$ F. Menna ${ }^{\text {b }}$, F. Remondino ${ }^{\text {b }}$ \\ ${ }^{\text {a }}$ Romanian National History Museum, 12 Calea Victoriei, 030026, Bucharest, Romania - \\ mariacorinanicolae@gmail.com \\ b 3D Optical Metrology (3DOM) unit, Bruno Kessler Foundation (FBK), via Sommarive 18, 38123, Trento, Italy - \\ $<$ nocerino, fmenna, remondino>@fbk.eu
}

KEY WORDS: photogrammetry, cultural heritage, marble, ceramics, reflective, bronze

\begin{abstract}
The process of creating 3D accurate and faithful textured models from 2D images has been a major endeavor within the cultural heritage field. This field has general requirements, such as accuracy, portability and costs, that are often integrated by more specific needs such as the integration of color information. The aim of this paper is to show how photogrammetry can be a valid and reliable techniques for creating 3D models of museum artefacts even in case of objects with materials featuring difficult optical properties (absorptivity, reflectivity, scattering), challenging texture and complex shape/geometry. The main objective is to establish some core specifications for data acquisition and modeling, in order to guarantee the scientific quality of data and the interoperability of 3D models with the archaeologists and conservators. All these aspects are taken into consideration and presented with three study cases (two statues - one made of marble and one made of bronze - and a restored ceramic jug). The established, comprehensive and accessible pipeline for the creation of complex artefacts 3D models in the field of cultural heritage is presented and discussed.
\end{abstract}

\section{INTRODUCTION}

3D digitization applications in the world of historical patrimony are directly connected to research and study, with the primary goal of producing heterogeneous material useful for documentation, restoration and as well valorization purposes. At the same time 3D data can be used for the creation of virtual models, reachable on digital media or on the web, thus intended both as a virtual version of a proper museum, but as well as a copy to study an archaeological artefact or a remote site. Digital representations are pushing a deep transformation in the cultural heritage domain and they are bringing new paths for generating social and economic benefits in the scientific community, in museums, as well as in the immediate surroundings.

Although the process of creating 3D models from surveyed data has represented a great benefit within the heritage field and a lot of one-click solutions are nowadays available, there are still many open issues raised by the design and implementation of a project (Remondino et al., 2013), by software solutions (Remondino et al., 2012; Koutsoudis et al., 2013) but also by artefacts with challenging texture and material, such as marble, metal surfaces, glass, etc. (Guidi et al., 2013). These problems apply both to photogrammetry and range sensors.

For small objects, like many of the exhibits preserved in museums, active triangulation sensors (laser or structured light) are likely the most feasible and reliable digitization solutions. Unfortunately, these systems are usually quite expensive and not all museums can afford such costs. Therefore, as in many other applications, photogrammetry is a valuable and attractive alternative. Photogrammetry is a 3D surveying and modelling method which has the major advantage of being low-cost, portable, flexible and able to deliver, at the same time, highly detailed geometries and textures. The objects best suited for automated image-based 3D reconstruction methods "have amorphous geometries, structured surfaces, many edges, many corresponding image points and an inhomogeneous coloring. Objects that produce rather bad or no results have unstructured, monochrome, translucent, reflective, and/or self-resembling surfaces" (Schaich, 2013). Nevertheless, most of the cultural heritage artefacts fall in the second category, being therefore problematic for image-based 3D modeling techniques.
The paper investigate this issue and reports the use of closerange photogrammetry for the generation of 3D models of artefacts stored in a museum which can result problematic due to their material - reflective, translucent and homogenous surfaces. The aim of this work is to show how a careful planning and a correct imaging acquisition allow to generate accurate and faithful 3D textured models of small exhibits even in loco (without moving the object from the museum) and with low-cost photographic equipment.

Surveying artefacts in museums can be a hard task due to many constraints dictated by the location characteristics (i.e. restricted spaces, unfavorable lighting conditions, etc.). Indeed passive techniques are very dependent on ambient lighting conditions, more than active sensors. External lights coming from windows or mixed color light temperature caused by different light sources hitting the object must be removed especially when reflective surfaces are being surveyed. A proper inspection of the location is therefore mandatory to reach the needed light control over the artefact and define the available space around the object.

In this study, three artefacts belonging to the Archaeological Collections of the Buonconsiglio castle in Trento (Italy) were taken into consideration. The three case studies, two statues one of marble and one of bronze - and a restored ceramic jug are all of small size. Consequently, very close-range photogrammetry in quasi-macro regime was planned to be used. At small ranges from the objects, additional difficulties arise due to the limited depth of field (Fig. 1) that demands good photographic expertise to capture sharp and contrasted images, mandatory for accurate 3D reconstruction (Menna et al., 2012). Marble is a translucent surface, bronze is reflective while in the case of the ceramic vessel, approximately $30 \%$ of the object is restored, thus textureless.

The undertaken work will be presented in three sections, each section corresponding to one artefact, focusing more on the winning methodology and lesson learnt than on the employed software. The photogrammetric workflow consisted of:

- image acquisition with a SLR digital camera;

- camera calibration and image orientation, using automated procedures able to extract homologues points between the images and the unknown camera parameters; 

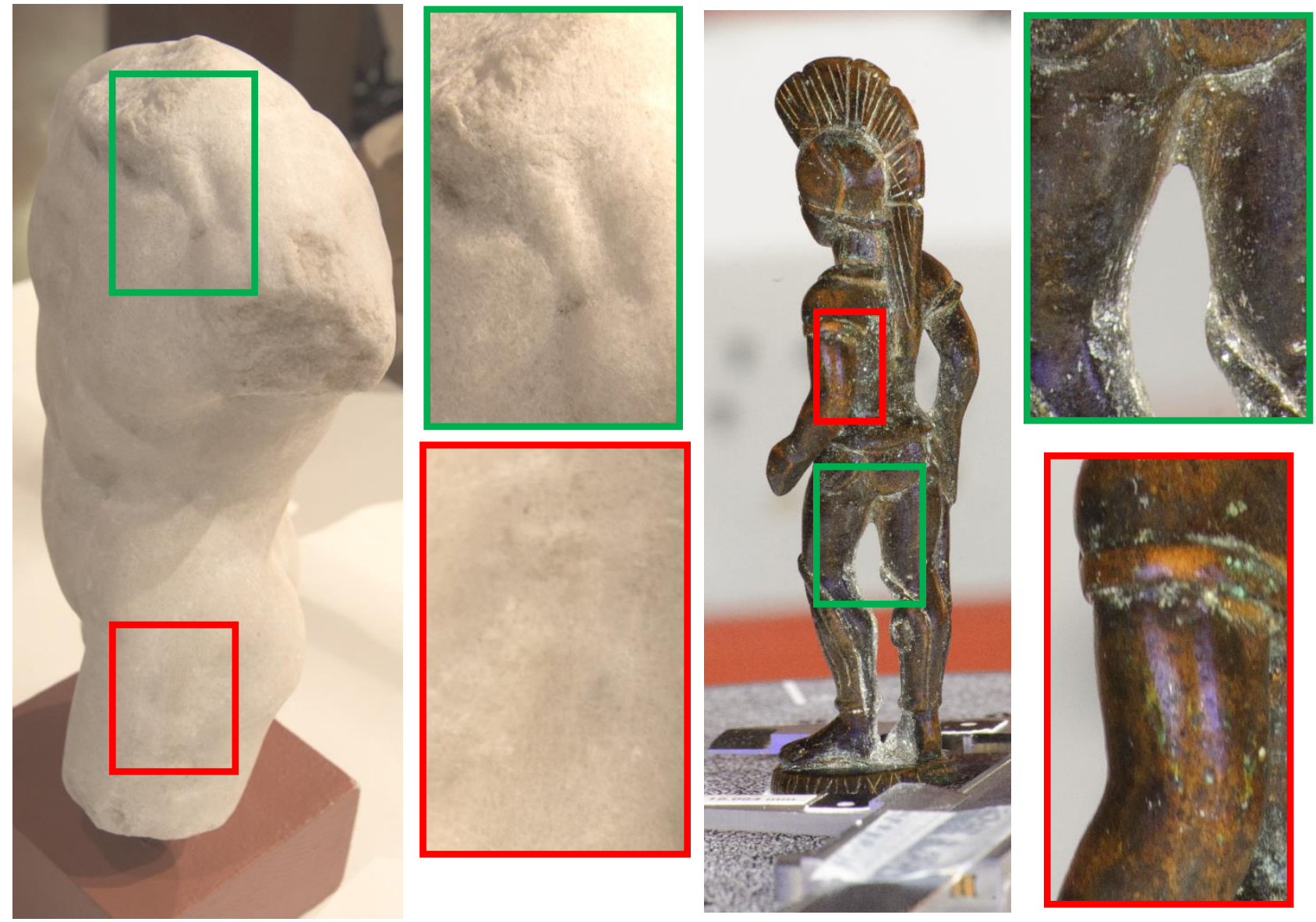

Figure 1: The two surveyed statues. Examples of very short depth of field on marble and bronze objects.

- dense matching and 3D reconstruction for the generation of dense point clouds;

- polygonal model generation and texture mapping for analyses and visualization.

\section{SELECTION OF THE PHOTOGRAMMETRIC PROCEDURES}

In order to exploit the cost-effectiveness of most recent photogrammetric developments, a quasi-automatic procedure was selected. The photogrammetric acquisition was carried out in a museum room during the closing day. Due to very long exposure time required by dim lights present in the museum, the camera was mandatorily mounted on a stable tripod. Indeed large f-numbers used to guarantee a sufficient depth of field yielded to very long exposure times.

In the case of the marble object, it was considered sufficient to use the museum illumination, since it produced a quite homogeneous illumination on the object, without strong shades and reflections. For the other two artefacts, it was necessary to use two photographic lamps mounted on tripods. The availability of sufficient and safe space for the photographic acquisition was a non-trivial issue. Indeed, the risk of hitting and damaging other heritage assets when moving around with bulky equipment can be really high and must not be underestimated.

Each artefact was placed on a turning table and rotated every time of at least $1 / 16$ of a round angle. In general, the angle is function of the object's shape and the minimum base-todistance ratio that is planned between the photographs. For objects of more complex shape it must be carefully selected and can be also kept not constant in a complete turn (depending on the complexity of the artefact). Several turns at different heights may be necessary to cover the whole object and also strengthen the camera network. Additional pictures for scaling the object may be also required if the scale bar is not clearly visible in the acquired images.

The advantage of rotating the object (when allowed) with respect to rotating the camera around it is that the space needed for the photographic acquisition can be significantly reduced an important factor considering the limited space normally available in deposits and conservation labs. At the same time, with this procedure, especially when photographing with limited depth of field, the camera-to-object distance can be controlled much more efficiently with respect to move the camera and the tripod around the object especially when photographic lamps on their stands are used. This results in a significant time saving. On the other hand the disadvantage when using turning tables is that within the imaged scene there are relative movements between the artefacts and the surrounding environment. Therefore, if automatic photogrammetric orientation is used, images have to be properly masked for removing parts of the images not belonging to the artefacts. When possible, setting up a homogeneous background (e.g. a backcloth) can solve the problem. Furthermore, in the 


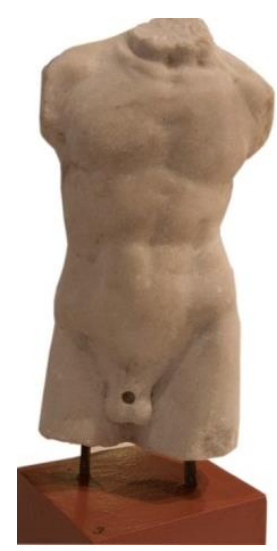

Front view

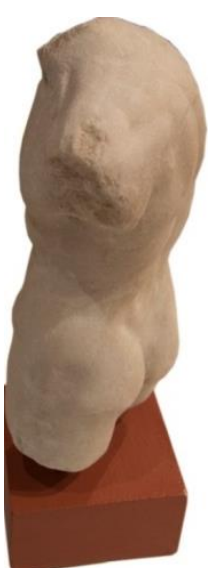

Side view

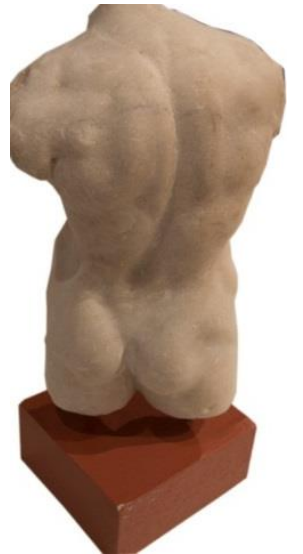

Back view

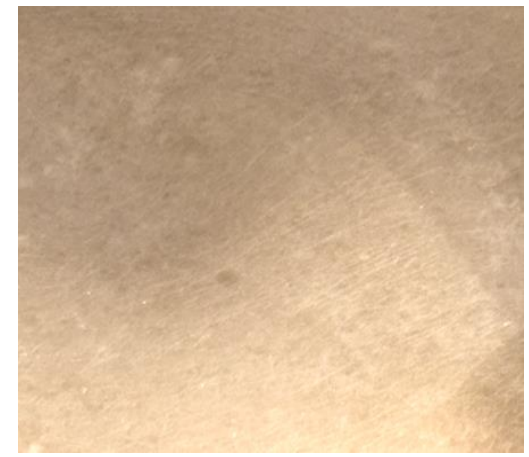

Enlargement of the object's texture

Figure 2: Marble male torso (Collections of Castello del Buonconsiglio Museum, Trento, Italy).
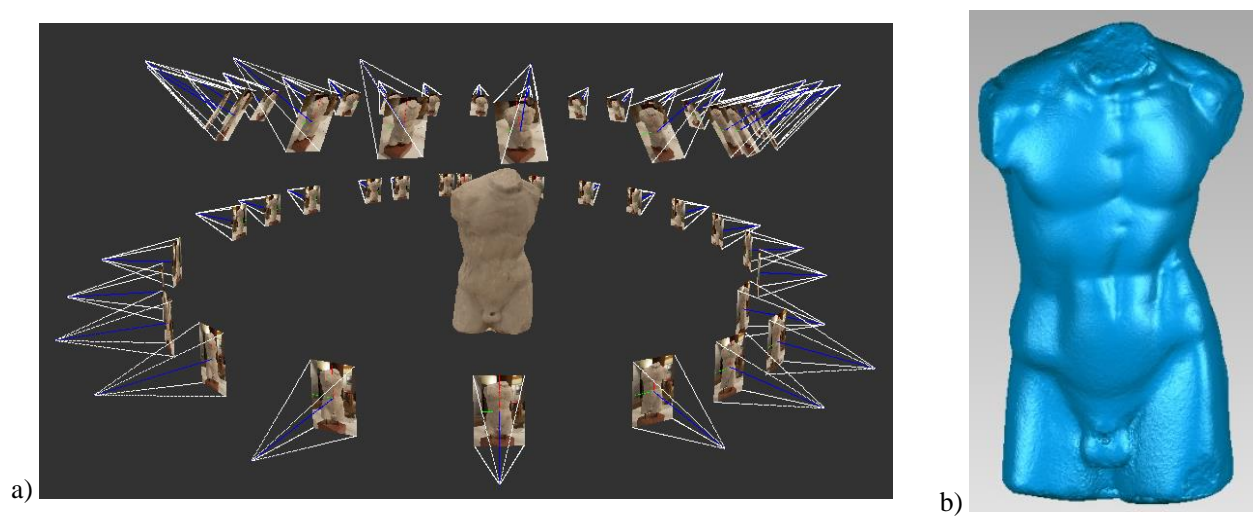

Figure 3: Imaging network for the marble torso (a). Mesh (b) and textured 3D model (c).

c)
(c).

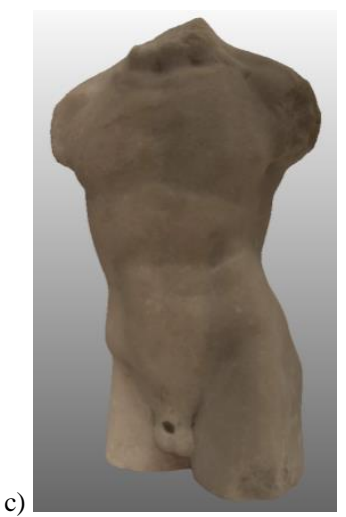

imaging acquisition, attention should be paid in optimizing the field of view, trying to cover the great part of the sensor with the object of interest.

The three case studies were selected for their characteristics, very common in the cultural heritage field and also known to be problematic for non-contact optical measuring systems. For the three artefacts different angular steps of the rotating table and acquisition heights were used. At least three additional pictures were taken for imaging a scale bar.

After the image acquisition, the following processing and modeling workflow was used:

- if necessary, the images were manually edited in order to mask the background, leaving only the artifact visible on the pictures;

- the images were automatically oriented;

- a reference scale bar was marked on the images in order to scale the photogrammetric model;

- an automatic dense image matching process was run;

- the derived dense point cloud was triangulated to obtain a mesh model;

- the mesh model was opportunely edited to correct for topological errors;

- the mesh model was textured with high resolution external texture generated from the original images.

\section{STUDY CASE 1 - MARBLE TORSO}

The marble torso has a size of $300 \times 150 \times 100 \mathrm{~mm}$ (Fig. 2). The artifact is dated to the early Roman period $\left(2^{\text {nd }}\right.$ cent. AD) and was selected for its material and colour. Figure 3 shows a particular of the material: the grain of the marble makes the object suitable for photogrammetric process. Indeed, marble, which is a crystalline rock aggregation of small packed grains of calcite, is known to generate errors and noise in range measurements when using an active sensor due to heterogeneous reflection properties encountered on the marble surface within the area illuminated (Godin et al., 2001; Guidi et al., 2009). A set of 53 photos was acquired with a 14.2 Megapixel DX-format sensor Nikon D3100 (pixel size of 5.26 $\mu \mathrm{m})$ mounting a $35 \mathrm{~mm}$ Nikkor lens with the focus locked. The imaging acquisition distance was about $520 \mathrm{~mm}$, implying an image scale of about $1: 15$ and a GSD of about $0.08 \mathrm{~mm}$. The obtained camera network is shown in Fig. 3a. The final mesh model (Fig. 3b) and external texture (Fig. 3c) were generated with an average resolution (mean triangle side length) of 0.3 $\mathrm{mm}$ and a mean GSD of $0.2 \mathrm{~mm}$, respectively.

\section{STUDY CASE 2 - BRONZE WARRIOR}

The second artefact taken into consideration is a small bronze statuette, about $150 \mathrm{~mm}$ high, depicting Mars, the Roman God of war (Fig. 4). The bronze statue represents a challenging object because of its material and size. In this case, the museum lights were not suitable for the survey, since they produced several specular reflections on the shiny bronze object. To avoid specular highlight that can compromise the photogrammetric process and produce a not faithful texture, some cold lamps were used and circular polarized filters were applied to camera lens and lamps. Cross polarization indeed reduces the amount of light hitting the sensor, requiring lower aperture number and/or higher exposure time. With matted surfaces, cross-polarization removes veiling glare and increases saturation and contrast. 


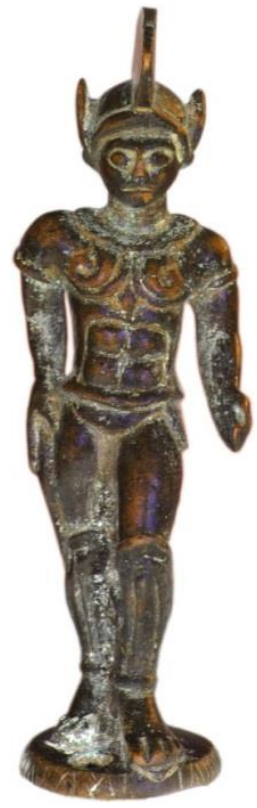

Front view

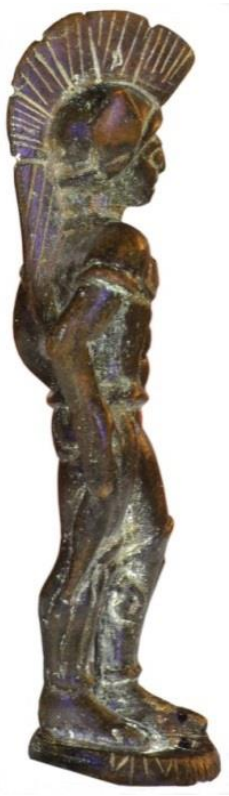

Side view

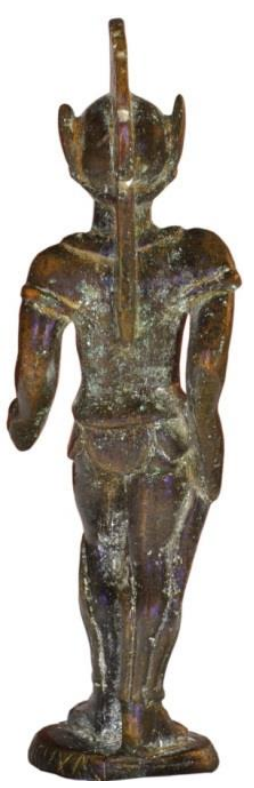

Back view
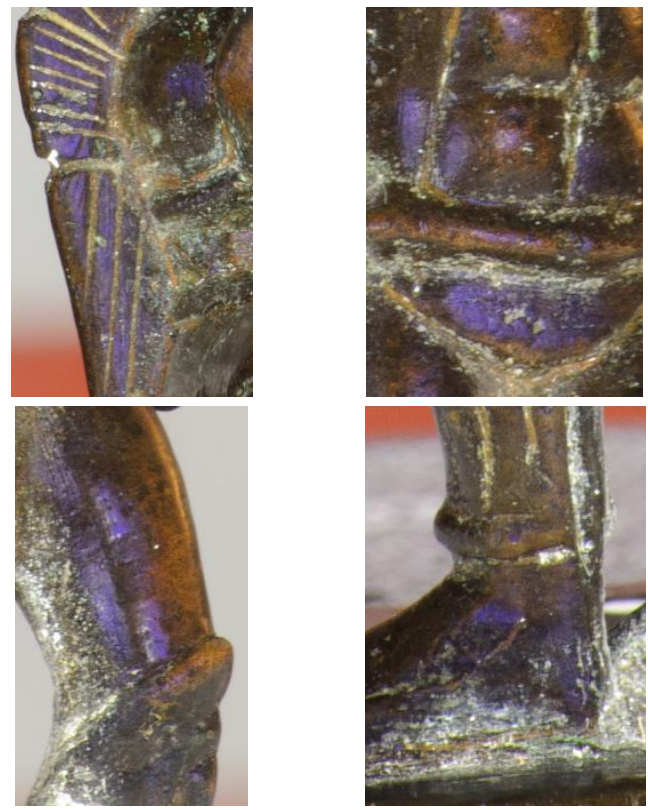

Enlargement of the object texture with bluish specular reflections

Figure 4. Bronze statuette depicting Roman Mars (Collections of Castello del Buonconsiglio Museum, Trento, Italy).

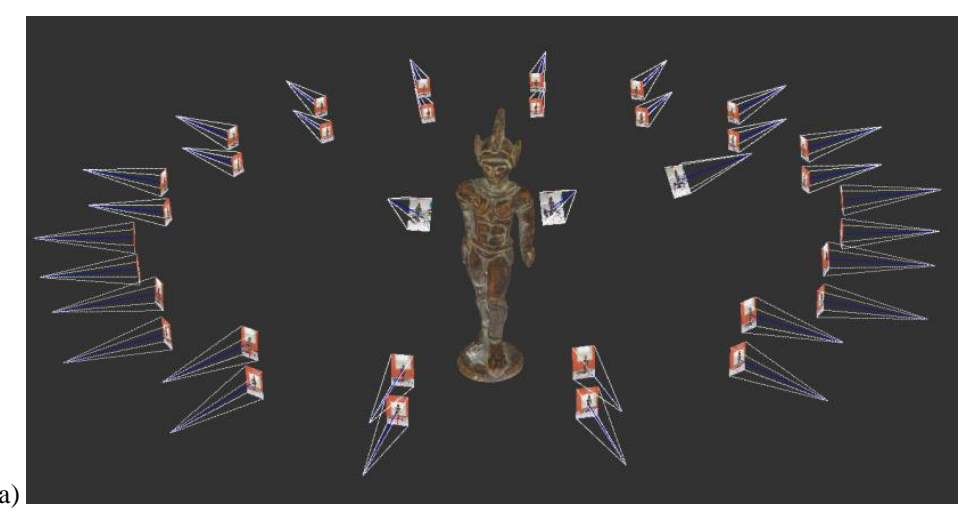

b)

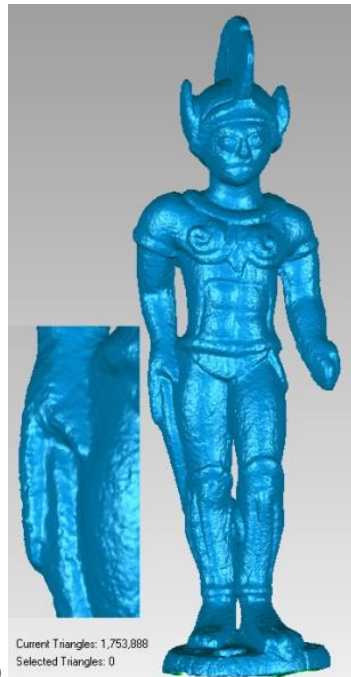

c)

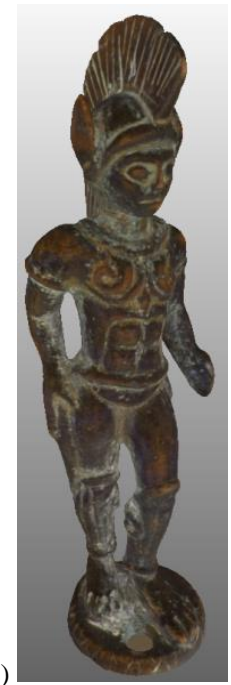

Figure 5: Derived camera network for the bronze warrior (a). Mesh model after the triangulation of the dense point cloud (b) and textured model (c)
Instead with certain metals and alloys some specular reflections still remain, causing artificial bluish colour where the specular reflections are stronger. This effect is still visible on the bronze warrior (Fig. 4 right). Thanks to the high number of acquired images, the effect is significantly reduced on the final 3D textured model. 35 photos (Fig. 5a) were acquired, using 24 Megapixel Nikon D3X full frame camera (pixel size of 5.95 $\mu \mathrm{m})$, with a $105 \mathrm{~mm}$ macro lens, ISO 400, f/16.0, and exposure time of $5.0 \mathrm{~s}$. The images were taken from a distance of approximately $63 \mathrm{~cm}$ from the object, obtaining a GSD less than $0.04 \mathrm{~mm}$.

The final mesh model (Fig. 5b) and external texture (Fig. 5c) were generated with an average resolution (mean triangle side length) less than $0.1 \mathrm{~mm}$ and a mean GSD of $0.1 \mathrm{~mm}$, respectively.

\begin{tabular}{|l|l|c|c|c|c|c|c|}
\hline \multicolumn{1}{|c|}{ Object } & Camera type & $\begin{array}{c}\text { Nominal focal } \\
\text { length }[\mathbf{m m}]\end{array}$ & $\begin{array}{c}\text { Pixel size } \\
{[\boldsymbol{\mu \mathbf { m } ]}}\end{array}$ & \# images & $\begin{array}{c}\text { Image GSD } \\
{[\mathbf{m m}]}\end{array}$ & $\begin{array}{c}\text { Mesh resolution } \\
{[\mathbf{m m}]}\end{array}$ & $\begin{array}{c}\text { Texture resolution } \\
{[\mathbf{m m}]}\end{array}$ \\
\hline Marble torso & Nikon D3100 & 35 & 5.26 & 53 & 0.08 & 0.3 & 0.2 \\
\hline Bronze statue & Nikon D3X & 105 & 5.95 & 35 & 0.04 & 0.1 & 0.1 \\
\hline Ceramic jug & Nikon D3100 & 35 & 5.26 & $55+40$ & 0.1 & 0.25 & 0.25 \\
\hline
\end{tabular}

Table 1: Summary of the main parameters of the case studies. 


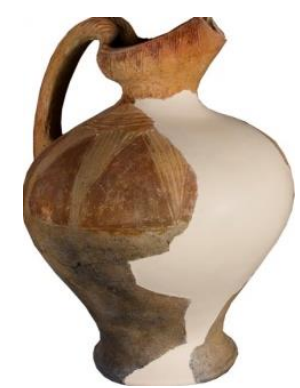

Right view

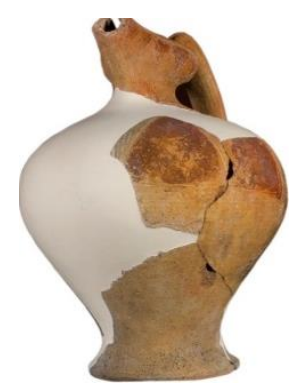

Left view

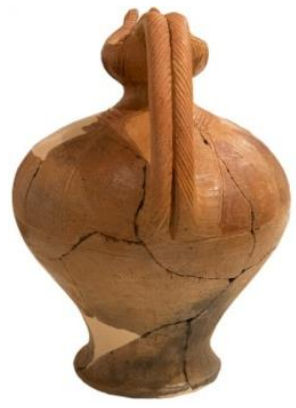

Back view

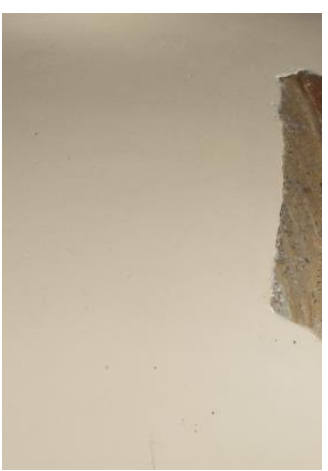

Enlargement of the featureless restored part without (left) and with the projected random pattern (right)

Figure 6. Ceramic jug (Collections of Castello del Buonconsiglio Museum, Trento, Italy).

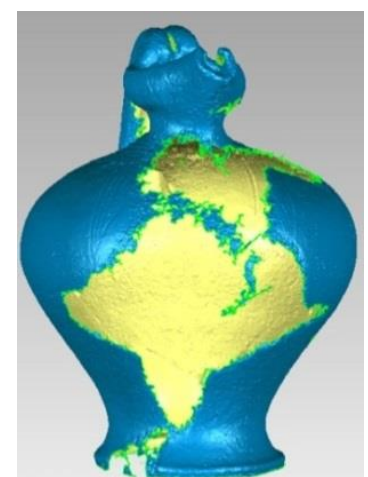

Figure 7: Reconstructed 3D model of the ceramic jug: the white textureless part was not reconstructed using a standard photographic equipment and photogrammetric approach.

\section{STUDY CASE 3 - CERAMIC JUG}

The third case study is represented by a restored ceramic jug (Fig. 6). According to the form of the pot, it is a kitchen ware, known as olpe, being employed for liquids. This type of ceramic is specific for the $1^{\text {st }}$ cent. AD of the Roman Empire. The object has approximately $30 \%$ of its body restored - according to restoration criteria, for this part it has been used a homogenous and textureless material (Figure 6). As photogrammetry needs corresponding features visible in different images in order to compute the exterior and interior parameters of the camera, the texture of the object is a primary factor in determining the future geometry of the imaged object. To test the reliability of automatic photogrammetric procedures in case of challenging texture, a first experiment was performed employing minimal photographic equipment. A 14.2 Megapixel DX-format sensor Nikon D3100 (pixel size of $5.26 \mu \mathrm{m}$ ) mounting a $35 \mathrm{~mm}$ Nikkor lens with the focus locked was used to take 73 photos ISO 1600 , $\mathrm{f} / 11.0$, and exposure time of $0.6 \mathrm{~s}-1.3 \mathrm{~s}$. In this test, the museum illumination was used; the camera was put on the tripod and the object rotated. With this minimal and simple set up, the restored, white part of the object was not reconstructed (Figure 7).

A second test was then carried out using a more sophisticated photographic configuration. For successfully applying an automatic and non-invasive photogrammetric processing without employing targets or directly interact with the object, a random pattern was projected on the artifact in order to create a synthetic texture on the featureless material (Figure 6).

Images were acquired with the same Nikon D3100 of the first case study. Additionally, polarized light was used for reducing the reflections. The camera to object distance was approximately $63 \mathrm{~cm}$ giving a GSD of about $0.1 \mathrm{~mm}$. For the pattern projection, a Dell M109S mini projector was used. A first complete set of 55 photos of the ceramic jug was acquired, without pattern projection (green pyramids in Fig. 8a).

A second set of 40 images was acquired, divided into five different strips. From each position two images were acquired: one with the projected pattern on the object and one without the pattern (red pyramids, Fig. 8b). It is noteworthy that for each single strip the relative position between the object and pattern remained fixed. Between two consecutive strips, the object was rotated until all the white textureless part was completely photographed. All the images without pattern were aligned in order to derive the interior and exterior camera parameters. Afterwards, for matching purposes, the images with the pattern were substituted to those from the same position but without pattern assigning the same camera parameters. Those images were then employed to reconstruct the geometry of the white part of the object. After the dense matching, a polygon mesh of approximately $0.25 \mathrm{~mm}$ mean triangle side length (Fig. 8c) and a high resolution $(0.25 \mathrm{~mm}$ GSD) texture (Fig. 8d) were produced.

\section{CONCLUSIONS}

The paper presented the photogrammetric surveying and 3D modeling of some museum artefacts with challenging texture and color, complex shape/geometry and material featuring difficult optical properties (absorptivity, reflectivity, scattering). An automated procedure was assembled in order to achieve satisfactory results in terms of geometry as well as texture. The most important aspects are geometry and, more critically, high fidelity colour information. Close-range photogrammetry was employed as an effective, low-cost and automated technique. In contrast to other more complex and expensive system solutions, close-range photogrammetry is relatively accessible to professionals in non-technical fields - such as curators or restorers - both in terms of software and hardware. Nevertheless high attention and experience is needed for the image acquisition otherwise even the most effective fully automated procedure will fail.

The first two artefacts highlighted a high level of noise in the final mesh models, most probably a consequence primarily of the reduced depth of field (see other experiences in Bitelli and Girardi, 2010; Gallo et al., 2013) and the material of the object. Having a reduced depth of field, points matching becomes more difficult and the result is a mesh with high noise level, more topological errors and a final textured 3D model with some areas out of focus. 

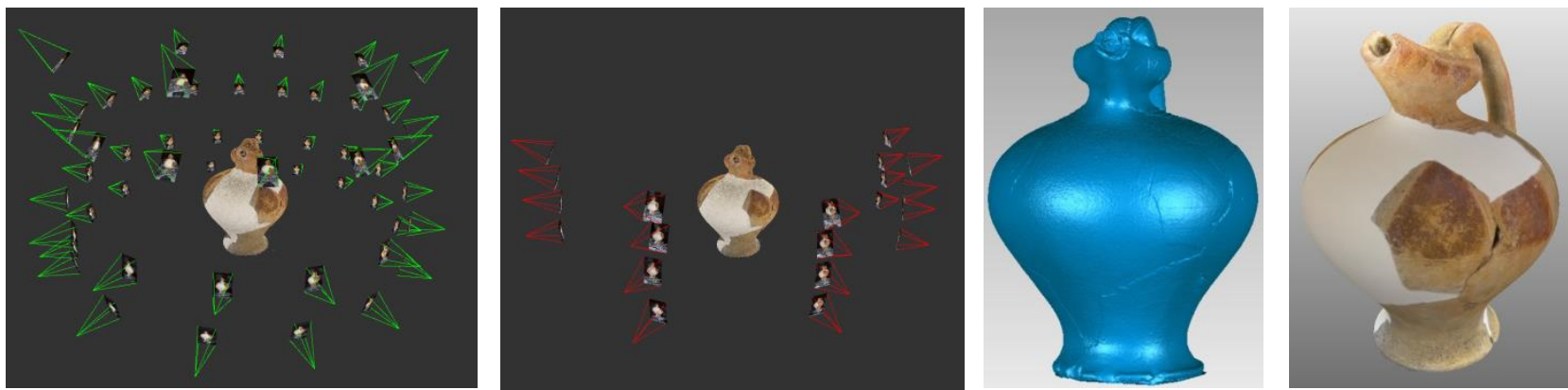

Figure 8: Imaging configuration for the ceramic jug: main imaging configuration without pattern projected onto the object (a); additional strips with images acquired with random pattern (b). Mesh model after the triangulation of the dense point cloud (c) and final textured 3D model (d).

As demonstrated in the reported results, although featureless textures represent a challenge for image-based documentation methods, there are solutions in order to deliver precise 3D geometric and textural information of these types of objects.

\section{ACKNOWLEDGEMENTS}

This work was funded by COST-Action TD 1201: Colour and Space in Cultural Heritage $(\mathrm{COSCH})$ within a Short Term Scientific Mission grant, performed at 3DOM-FBK, Trento (Italy), from November-December 2013. The work is also partially supported by the 3D-ICONS project funded under the EC's ICT Policy Support Programme. The authors are also thankful to the Buonconsiglio Castle personnel for their support and help during the acquisitions.

\section{REFERENCES}

Bitelli, G., Girardi, F., 2010: Problematiche nel rilievo e modellazione tridimensionale di oggeti di piccole dimensioni nel campo dei Beni Culturali. Proc. $14^{\text {a }}$ Conferenza Nazionale ASITA, pp. 285-290 (available at: http://www.attiasita.it/ASITA2010/Pdf/241.pdf, last accessed on May 15, 2014).

Gallo, G., Muzzupappa, A., Bruno, F., 2013: 3D reconstruction of small sized objects from a sequence of multi-focused images. Journal of Cultural Heritage, Vol. 15(2), pp. 173-182

Guidi, G., Remondino, F., Russo, M., Spinetti, A, 2009: Range sensors on marble surfaces: quantitative evaluation of artifacts. Proc. Videometrics, Range Imaging and Applications X, Proc. of SPIE Optics+Photonics, Vol. 7447, pp. 744703-744703.

Guidi, G., Rodríguez Navarro, O., Gonizzi-Barsanti, S., Micoli, L.L., Russo, M., 2013: Quick textured mesh generation in Cultural heritage digitization. Proc. Built Heritage 2013 Conference - Monitoring Conservation and Management, pp. 874-882.

Godin, G., Rioux, M., Beraldin, J.-A., Levoy, M., Cournoyer, L., 2001. An Assessment of Laser Range Measurement of Marble Surfaces. Proc. of the 5th Conference on Optical 3-D Measurement Techniques, Vienna, Austria, 49-56.

Gordon, S., Lichti, D. D., Stewart, M.P., Tsakiri, M., 2001. Metric performance of a high-resolution laser scanner. Proc. of Videometrics and Optical Methods for 3D Shape Measurement, SPIE Vol. 4309, pp. 174-184.
Lichti, D. D., Harvey, B. R., 2002: The effects of reflecting surface properties on Time-of-Flight laser scanner measurements. Int. Archives of Photogrammetry, Remote Sensing and Spatial Information Sciences, Vol. 34(4).

Koutsoudis, B. Vidmar, F. Arnaoutoglou, 2013: Performance evaluation of a multi-image $3 \mathrm{D}$ reconstruction software on a low-feature artifact. Journal of Archaeological Science, Vol. 40 pp. 4450-4456, http://dx.doi.org/10.1016/j.jas.2013.07.007.

Menna, F., Rizzi, A., Nocerino, E., Remondino, F., Gruen, A., 2012: High resolution 3D modeling of the Behaim globe. Int. Archives of Photogrammetry, Remote Sensing and Spatial Information Sciences, Vol. 39(5), pp. 115-120. XXII ISPRS Congress, Melbourne, Australia

Remondino, F., Del Pizzo, S., Kersten, T., Troisi, S., 2012: Low-cost and open-source solutions for automated image orientation - A critical overview. Proc. EuroMed 2012 Conference, LNCS 7616, pp. 40-54.

Remondino, F., Menna, F., Koutsoudis, A., Chamzas, C., ElHakim, S., 2013: Design and implement a reality-based 3D digitisation and modelling project. Proc. IEEE Conference "Digital Heritage 2013", Vol. 1, pp. 137-144.

Schaich, M. 2013: Combined 3D scanning and photogrammetry surveys with 3D database support for archaeology \& cultural heritage. A practice report on ArcTron's information system aSPECT $^{3 \mathrm{D}}$. Proc. Photogrammetric Week 2013, D. Fritsch (ed.). Wichmann, Berlin/Offenbach, pp. 233-246. 